\title{
The Chromosomal Architecture of Cicer anatolicum Alef., a Wild Perennial Relative of Chickpea
}

\author{
F. Ahmad \\ Agriculture Canada, Research Station, 2560 Hochelaga Blvd., \\ Sainte-Foy Québec, Canada G1V 2J3
}

Accepted June 14, 1989

The cultivated chickpea, Cicer arietinum L. is an important food grain legume crop in the Asian continent. It is known to have 8 annual and 34 perennial relatives (van der Maesen 1987). Karyotype studies (Ahmad et al. 1987a), seed storage protein profiles (Ladizinsky and Adler 1975, Ahmad and Slinkard 1989) and interspecific hybridization studies (Ladizinsky and Adler 1976, Ahmad 1988) lend support to the suggestion that cultivated chickpea originated from C. reticulatum Lad. It is, however, believed that the first essential step in the evolution of annual grain legumes is the evolution of annual state from perennial state. The discovery of wild annual ancestor of chickpea should, therefore, represent evolution only at the secondary level and, thus, the perennial relatives must be studied to understand evolution at the primary level.

C. anatolicum Alef. is one of the 34 wild perennial relatives of the cultivated chickpea (van der Maesen 1987). It is found growing in the wild state on sandy, rocky and rubble slopes at altitudes of 1150 to $3300 \mathrm{~m}$ in Turkey, N. W. Iran, N. Iraq and Soviet Armenia. The plants are woody root stocks, straight or ascending, branched, 20 to $40 \mathrm{~cm}$ long. The leaf is always compound with 8 to 14 leaflets and ends in a tendril. It has dark blue to violet-colored flowers showing typical Papilionaceous morphology with 20 to $45 \mathrm{~mm}$ long peduncles. The pods are elliptical-oblong, 20 to $30 \times 10 \mathrm{~mm}$ in size with dark brown to black, subglobular, beaked seeds, 5 to $7 \mathrm{~mm}$ in size (van der Maesen 1972).

There is only one report of the chromosome number in this species (van der Maesen 1972) and as pointed out by Polhill and van der Maesen (1985) it is not sure as to whether it is $2 n=14$ or 16 . There is no report to date on the detailed karyotype of this species. Thus, the objective of this study was to confirm the chromosome number, to prepare a standard karyotype and to develop a karyotypic formula for $C$. anatolicum. This information should be useful in determining phylogenetic relationships among the different species of the genus Cicer.

\section{Materials and methods}

Seed samples of $C$. anatolicum were very kindly supplied by Dr. Walter Kaiser of the United States Dept. of Agriculture (Pullman, Washington). Seed coat was mechanically removed and the seeds then germinated on moist filter paper in the laboratory at approximately $21^{\circ} \mathrm{C}$. The growing root tips, from $1.0-1.5 \mathrm{~cm}$ long roots, were excised and pretreated with chilled distilled water at $1-2^{\circ} \mathrm{C}$ for $12 \mathrm{hr}$. After cold treatment the root tips were fixed in Farmer's fixative ( 3 parts $95 \%$ ethanol: 1 part glacial acetic acid) to which traces of ferric chloride $\left(\mathrm{FeCl}_{3}\right)$ were added to enhance staining.

Root tips were stained by Feulgen method after hydrolysis in $1 \mathrm{~N} \mathrm{HCl}$ for 13 min at $60^{\circ} \mathrm{C}$. They were then thoroughly washed with distilled water after which they were treated with $4 \%$ pectinase enzyme solution for approximately $6 \mathrm{hr}$, to digest the cell walls. Stained and 
enzyme treated root tips were then left overnight in distilled water at room temperature. Root tips were then squashed in $1 \%$ acetocarmine stain. Photomicrographs were taken on a Tech Pan 2415 film with a Zeiss research microscope fitted with a photomicrographic camera.

The length of each chromosome was measured with the help of dial caliper and was expressed as a percentage of the total length of the diploid chromosome complement $(\mathrm{L} \%)$. The centromere position was characterized by the Pa-value, which is the ratio of the long and short arm of the chromosome, excluding the secondary constriction. To provide a better comparison among species and to avoid any confusion, chromosome types were defined on the basis of position of the primary constriction (long/short arm ratio), viz., 1.00-1.25 as metacentric, $1.26-1.75$ as submetacentric and 1.76 onwards as acrocentric with telocentric being obvious by itself. Chromosomes were also defined on the basis of total length, i. e. $\mathrm{A}=>3.10 \mu \mathrm{m}, \mathrm{B}=2.51-3.10 \mu \mathrm{m}, \mathrm{C}=1.91-2.50 \mu \mathrm{m}$ and $\mathrm{D}=<1.91 \mu \mathrm{m}$. Karyological data were collected from the eight most definitive cells observed, with similar levels of chromosome condensation, and the average measurements were used.

Table 1. Somatic chromosome measurements of Cicer anatolicum Alef.

\begin{tabular}{ccccccc}
\hline \hline $\begin{array}{c}\text { Chromosome } \\
\text { number }\end{array}$ & $\begin{array}{c}\text { Chromosome } \\
\text { type*2 }\end{array}$ & $\begin{array}{c}\text { Long } \\
\text { arm } \\
(\mu \mathrm{m})\end{array}$ & $\begin{array}{c}\text { Short } \\
\text { arm } \\
(\mu \mathrm{m})\end{array}$ & $\begin{array}{c}\text { Total } \\
\text { length } \\
(\mu \mathrm{m})\end{array}$ & Pa-value*3 & $\begin{array}{c}\mathrm{L} \\
(\%)^{* 4}\end{array}$ \\
\hline 1 & Acro & $2.32^{* 1}$ & 1.01 & $3.33 \pm .12$ & $2.31 \pm .07$ & $17.64 \pm .53$ \\
2 & $\mathrm{Sm}$ & 1.62 & 0.97 & $2.59 \pm .09$ & $1.71 \pm .13$ & $13.72 \pm .41$ \\
3 & $\mathrm{Sm}$ & 1.55 & 1.01 & $2.54 \pm .18$ & $1.54 \pm .16$ & $13.45 \pm .93$ \\
4 & $\mathrm{Sm}$ & 1.33 & 1.01 & $2.39 \pm .03$ & $1.27 \pm .13$ & $12.66 \pm .35$ \\
5 & $\mathrm{Sm}$ & 1.36 & 0.87 & $2.22 \pm .07$ & $1.58 \pm .19$ & $11.76 \pm .43$ \\
6 & $\mathrm{Sm}$ & 1.20 & 0.91 & $2.11 \pm .20$ & $1.32 \pm .09$ & $11.18 \pm .87$ \\
7 & $\mathrm{Sm}$ & 1.15 & 0.88 & $2.03 \pm .08$ & $1.31 \pm .03$ & $10.75 \pm .42$ \\
8 & $\mathrm{M}$ & 0.86 & 0.83 & $1.69 \pm .08$ & $1.04 \pm .04$ & $8.95 \pm .39$ \\
\hline
\end{tabular}

*1 Secondary constriction was located $1.37 \mu \mathrm{m}$ from the primary constriction.

*2 M, Sm and Acro refer to metacentric, submetacentric and acrocentric chromosome, respectively.

*3 Long arm/Short arm ratio \pm standard error.

* Length as percentage of total diploid chromosome length of the species \pm standard error.

\section{Results and discussion}

The diploid chromosome number in all the root tips was 16 (Fig. 1). A chromosome number of $2 n=14$ was never observed in any cell of any root tip as previously reported by van der Maesen (1972). Mean length of the haploid chromosome complement, recorded from eight cells, was $18.88 \pm .97 \mu \mathrm{m}$. However, this varied slightly in different cells depending upon the degree of condensation of the chromosomes. Measurements of the chromosome complement are presented in Table 1.

Based on total length, chromosome pairs were arranged from 1 to 8 in order of decreasing length (Fig. 2). Chromosome length of the complement ranged from 1.69 to 3.33 $\mu \mathrm{m}$, with a mean chromosome size of $2.36 \pm .21 \mu \mathrm{m}$. Based on the location of the primary constriction (centromere), secondary constriction (nucleolar organizing region) and size of the chromosomes, the following karyotypic formula was developed for $C$. anatolicum: $\mathrm{K}(\mathrm{n}=8)$ $=1_{\mathrm{Sc}} \mathrm{A}^{\mathrm{Acro}}+2 \mathrm{~B}^{\mathrm{Sm}}+4 \mathrm{C}^{\mathrm{Sm}}+1 \mathrm{D}^{\mathrm{M}}$; where $\mathrm{M}, \mathrm{Sm}$ and Acro signify metacentric, submetacentric and acrocentric chromosomes, respectively and A, B, C and D refer to chromosome size classes as defined earlier. The secondary constriction is denoted by $\mathrm{Sc}$ in the formula.

The secondary constriction was present on chromosome 1, about $1.37 \mu \mathrm{m}$ from the primary constriction and was quite conspicuous in both the homologues of all the cells observed.

An idiogram for $C$. anatolicum may be seen in Fig. 3. The chromosome complement 
which has been divided into three groups depending upon the location of the primary constriction, can be summarized as follows:

(1) One pair of metacentric chromosomes. This is the shortest chromosome (number 8) of the complement.

(2) Six pairs of submetacentric chromosomes. These are chromosomes 2 to 7 . Chromosomes 4,6 and 7 are barely submetacentric while chromosome 2 is the most highly submetacentric pair.

(3) One pair of acrocentric chromosomes. This is the longest chromosome (number 1) of the complement which is characterized by a conspicuous secondary constriction on the long arm. The secondary constriction was located $1.37 \mu \mathrm{m}$ from the primary constriction.

The karyotype concept has been extensively used in characterizing and distinguishing chromosomes of different species. Mitotic karyotype analyses are also helpful in studying evolutionary problems (Gottschalk 1972). The karyotype of the cultivated chickpea, Cicer arietinum, has already been reported (Mercy et al. 1974, Ahmad and Godward 1980, Sharma and Gupta 1982, Lavania and Lavania 1983, Kutarekar and Wanjari 1983, Ahmad et al. 1987a). However, this is the first published report of the karyotype of C. anatolicum.
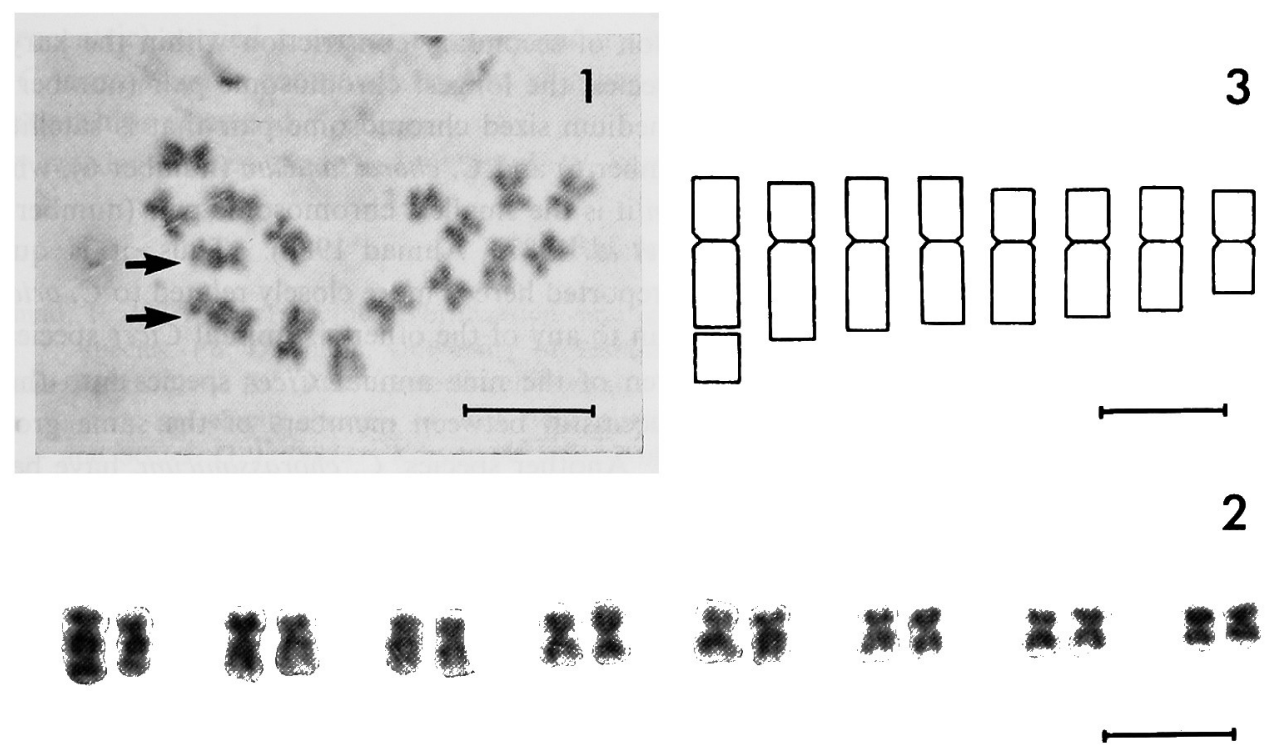

Figs. 1-3. Chromosomal structure of Cicer anatolicum Alef. 1, a somatic cell of C. anatolicum; arrows indicate the chromosome pair with secondary constriction. 2, karyotype of $C$. anatolicum; note the secondary constriction on the long arm of chromosome number 1.3 , idiogram of somatic chromosomes of $C$. anatolicum. Bar in Figs. 1 and 2 represent $5 \mu \mathrm{m}$, while in Fig. 3 represent $2 \mu \mathrm{m}$.

Various karyotype analyses of $C$. arietinum, done by different workers, have given the following characteristic features:

(1) A pair of long chromosomes, distinctly satellited and submetacentric.

(2) Six pairs of medium sized metacentric to submetacentric chromosomes.

(3) A pair of very short chromosomes.

There are only minor differences in gross morphology of the karyotypes of $C$. anatolicum, $C$. arietinum, $C$. reticulatum and $C$. echinospermum Dav. In all these three annual Cicer species and $C$. anatolicum, it is always the longest chromosome (number 1) that is satellited (Ahmad et al. 1987a). Mean haploid chromosome complement length, mean chromosome 
length and ranges in chromosome sizes within a chromosome complement are very much comparable in all these four species. The minor karyotypic differences are, however, exhibited in the number of chromosomes of different types (metacentric, submetacentric and acrocentric). Thus, while $C$. reticulatum and $C$. arietinum have five metacentric and three submetacentric chromosome pairs, $C$. echinospermum has three metacentric and five submetacentric chromosome pairs (Ahmad et al. 1987a), whereas C. anatolicum has one metacentric, six submetacentric and one acrocentric pairs of chromosomes. It should be noted that chromosomes number 4, 6 and 7 in $C$. anatolicum are barely submetacentric (Table 1) and could possibly be metacentric. Such minor differences in chromosome arm ratio are sometimes produced through differential chromatin condensation due to different pretreatments and reduced precision of human vision (Gottschalk 1972). Thus, it is clear that the above mentioned four species have karyotypes that resemble very closely to each other.

Karyotypes of the remaining six annual Cicer species, viz. C. pinnatifidum Jaub and Spach, C. bijugum Rech., C. chorassanicum (Bge) M. Pop., C. judaicum Boiss., C. yamashitae Kitam. and $C$. cuneatum Rich., are quite different from the previously described four species. All these species are characterized by symmetrical karyotypes and comparatively smaller mean haploid chromosome complement lengths and mean chromosome sizes. The most important difference, however, is in the position of secondary constriction within the karyotype (Ahmad et al. 1987a). In all these six species, the longest chromosome pair (number 1) is never satellited. Instead, it is one of the medium sized chromosome pair that is satellited in $C$. pinnatifidum (number 5), C. bijugum (number 6) and $C$. chorassanicum (number 6), while in $C$. judaicum, $C$. yamashitae and $C$. cuneatum it is the smallest chromosome pair (number 8) of the complement that is satellited (Ahmad et al. 1987a, Ahmad 1988). Thus, it is quite obvious that the karyotype of $C$. anatolicum reported here is more closely related to $C$. arietinum, C. reticulatum and C. echinospermum, than to any of the other six annual Cicer species.

Ladizinsky and Adler (1976) divided seven of the nine annual Cicer species into three crossability groups such that crosses were successful between members of the same group but not between members of different groups. Another species, $C$. chorassanicum, have been recently added to the second crossability group of Ladizinsky and Adler (1976), with the first report of the hybrid C. judaicum $\times$ C. chorassanicum (Ahmad et al. 1987b), along with C. pinnatifidum, C. bijugum and C. judaicum (Ahmad 1988). The three possible interspecific hybrids involving members of the first group, viz. C. arietinum, $C$. reticulatum and C. echinospermum, have already been produced (Ladizinsky and Adler 1976, Ahmad 1988). The $\mathrm{F}_{1}$ hybrid $C$. arietinum $\times C$. reticulatum gives fertile offsprings and shows normal chromosome pairing of 8 bivalents, whereas $C$. echinospermum differs from $C$. arietinum and $C$. reticulatum by one reciprocal translocation and their hybrids are sterile (Ladizinsky and Adler 1976). Quite interestingly the karyotypes of these three species are not only similar to each other but also quite different from that of the other species belonging to the crossability groups II and III. Such karyotypic similarities and crossability/genetic relationships raise an important curiousity as to whether there is any valid relationship between karyotypic similarity and crossability in the genus Cicer, and if this could give us any insight into genetic relationships.

So far, no one has attempted interspecific hybridization between $C$. anatolicum and $C$. arietinum for either evolutionary or practical purposes. While everyone embarks on the annual species with more enthusiasm, this is not the only reason for the lack of such studies. The wild perennial relatives of Cicer are extremely poorly represented in the world germplasm collection due to political and financial restrains. Even if there are a few accessions in the germplasm it had been difficult to maintain them (van der Maesen 1980). Cicer anatolicum did not flower in Saskatoon, for interspecific hybridization purposes, despite vernalization 
of the plants and growing them in growth cabinet with controlled environmental conditions. It is important that other Cicer species also be studied cytologically to gain further understanding regarding genetic relationships and phylogeny in the genus Cicer.

\section{Acknowledgements}

This research was conducted while the author was at the Department of Crop Science and Plant Ecology of the University of Saskatchewan, Saskatoon, Canada. The facilities provided to the author are sincerely acknowledged.

\section{Summary}

Chromosomal architecture of Cicer anatolicum Alef,, a wild perennial relative of chickpea, was studied to assist in determining phylogenetic relationships within the genus Cicer L. The diploid chromosome number was confirmed as $2 n=16$. Mean haploid chromosome complement length and mean chromosome length were 18.88 and $2.36 \mu \mathrm{m}$, respectively. The karyotype was asymmetrical and characterized by one metacentric, six submetacentric and one acrocentric chromosome pairs. The longest chromosome pair (acrocentric) carried a conspicuous secondary constriction on the long arm. The karyotype of C. anatolicum is compared to that of other annual Cicer species and further phylogenetic relationships discussed.

Key words: Cicer, chromosome, cytology, karyotype

\section{References}

Ahmad, F. 1988. Interspecific hybridization and genetic relationships among the annual Cicer L. species. Ph. D Thesis. University of Saskatchewan, Canada. pp. 181.

- and Slinkard, A. E. 1989. Genetic relationships in the genus Cicer L., as revealed by polyacrylamide gel electrophoresis of seed storage protein. (Submitted for publication).

-, - and Scoles, G. J. 1987a. Karyotypic analysis of the annual Cicer L. species. The Genetics Society of Canada Bulletin 18 (Suppl. 1): 130.

- - and - $1987 \mathrm{~b}$. The cytogenetic relationship between Cicer judaicum Boiss. and Cicer chorassanicum (Bge) M. Pop. Genome 29: 883-886.

Ahmad, S. and Godward, M. B. E. 1980. Cytological Studies on the cultivars of Cicer arietinum L. from Pakistan. Caryologia 33: 55-67.

Gottschalk, W. 1972. The study of evolutionary problems by means of cytological methods. Egypt. J. Genet. Cytol. 1 : 73-84.

Kutarekar, D. R. and Wanjari, K. B. 1983. Karyomorphological studies in some of the varieties of bengal gram (Cicer arietinum Linn.). Cytologia 48: 699-705.

Ladizinsky, G. and Adler, A. 1975. The origin of chickpea as indicated by seed protein electrophoresis. Israel J. Bot. 24: 183-189.

- and - 1976. Genetic relationships among the annual species of Cicer L. Theor. Appl. Genet. 48: 197-203.

Lavania, U. C. and Lavania, S. 1983. Karyotype studies in Indian pulses. Genet. Agr. 37: 299-308.

Mercy, S. T., Kakar, S. N. and Chowdhury, J. B. 1974. Cytological studies in three species of the genus Cicer. Cytologia 39: 383-390.

Polhill, R. M. and van der Maesen, L. J. G. 1985. Taxonomy of grain legumes. Pages 3-36 in R. J. Summerfield and E. H. Roberts (Eds.). Grain Legume Crops. Collins Professional and Technical Books, London, UK.

Sharma, P. C. and Gupta, P. K. 1982. Karyotypes in some pulse crops. The Nucleus 25: 181-185.

van der Maesen, L. J. G. 1972. Cicer L., a monograph of the genus, with special reference to the chickpea (Cicer arietinum L.), its ecology and cultivation. Thesis Agric. Univ. Wageningen Meded. Landbouwhogesch, Wageningen 72-10, 342 pp.

- 1980. Growing wild chickpeas. Int. Chickpea Newsl. 2: 3-4.

-. 1987. Origin, history and taxonomy of chickpea. Pages 11-34 in M. C. Saxena and K. B. Singh (Eds.). The Chickpea. CAB International Publications, UK. 